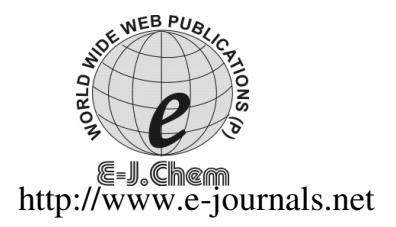

ISSN: 0973-4945; CODEN ECJHAO

E-Journal of Chemistry

2011, 8(1), 281-287

\title{
Spectrophotometric Determination of Reboxetine through Condensation and Diazo-Coupling Reactions
}

\author{
K. SRIKANTH and K.A. EMMANUEL* \\ Department of Chemistry, Sir C R Reddy (A) College \\ Eluru-534 007, Andhra Pradesh, India \\ emmikola@gmail.com
}

Received 14 March 2010; Revised 9 June 2010; Accepted 17 July 2010

\begin{abstract}
In the present study, two simple, sensitive and reproducible visible spectrophotometric methods were developed for the determination of reboxetine in pure form and in pharmaceutical formulations. The methods involve acid hydrolysis of reboxetine methane sulphonate (Reboxetine as methane sulphonate) and the product obtained was used for the estimation. Out of the two methods developed in the laboratory, the first method involves the condensation reaction of hydrolysed reboxetine methane sulphonate with ethyl acetoacetate in sulphuric acid medium and the second method involves the diazocoupling reaction of hydrolysed reboxetine methane sulphonate with diazotized $p$-sulphanilic acid in alkaline medium. They have absorption maxima at $400 \mathrm{~nm}$ and $430 \mathrm{~nm}$ respectively and obey Beer's law in the concentration ranges of $0.5-0.3 \mu \mathrm{gmL}^{-1}$ and $1.0-7.5 \mu \mathrm{gmL}^{-1}$ respectively. Results of analysis were validated statistically and by recovery studies. The apparent molar absorptivity values $\left(\epsilon_{\max }\right)$ obtained are $7.549 \times 10^{4} \mathrm{~L} \mathrm{~mol}^{-1} \mathrm{~cm}^{-1}$ and $2.656 \times 10^{4} \mathrm{Lmol}^{-1} \mathrm{~cm}^{-1}$ respectively. Both these have correlation coefficient value of 0.9999 . The proposed methods have good precision and accuracy.
\end{abstract}

Keywords: UV Visible digital spectrophotometer, Reboxetine methane sulphonate, Ethyl acetoacetate, $p$-Sulphanilic acid.

\section{Introduction}

Reboxetine, (2R)-rel-2-[(R)-(2-ethoxy phenoxy) phenyl methyl] morpholine (Figure 1), is the first of a new class of antidepressant drugs, which selectively inhibit the neuronal reuptake of noradrenaline. It also has weak effect on serotoxin reuptake. It is devoid of any affinity for neurotransmitter receptors nor does it inhibit mono amine oxidases A or B. It is given as the mesilate (methane sulphonate) for the treatment of depression with doses expressed as reboxetine. $5.23 \mathrm{mg}$ of reboxetine mesilate is approximately equivalent to $4 \mathrm{mg}$ of reboxetine. 
A very few physicochemical methods were appeared in the literature for the assay of reboxetine methane sulphonate (REB) in biological fluids and pharmaceutical formulations. The methods so far reported include high-performance liquid chromatography (HPLC) ${ }^{1-10}$ of different modes and detectors, capillary electrophoresis $(\mathrm{CE})^{11,12}$, gas chromatography-mass spectroscopy $(\mathrm{GC}-\mathrm{MS})^{13}$ and visible spectrophotometry ${ }^{14}$. The analytically important functional groups of REB were not properly exploited for designing suitable spectrophotometric methods for the determination REB.

Therefore in the present study, new sensitive and flexible visible spectrophotometric methods were developed based on the reactivity of REB with reagents such as ethyl acetoacetate in sulphuric acid medium and diazotized $p$-sulphanilic acid to produce condensation product and diazo-coupling product respectively. These were based on the presence of phenoxy ethyl (acid hydrolysis yields phenolic hydroxyl) group in REB.

A simple and sensitive UV spectrophotometric method was developed by dissolving the drug in methanol for the determination of REB in pure or pharmaceutical formulations (tablets) and adopted it as a reference method to compare the results obtained by proposed methods.<smiles>CCOc1ccccc1OC(c1cccc(C(=O)O)c1)C1CNCCO1</smiles>

Figure 1. Reboxetine methane sulphonate (REB)

\section{Experimental}

An Elico, UV Visible digital spectrophotometer with $1 \mathrm{~cm}$ matched quartz cells were used for the spectral and absorbance measurements. An Elico LI-120 digital pH meter was used for $\mathrm{pH}$ measurements.

\section{Preparation of standard solution of hydrolysed REB (HREB)}

$25 \mathrm{mg}$ of reboxetine methane sulphonate was boiled with $10 \mathrm{~mL}$ of $5 \mathrm{~N} \mathrm{HCl}$ in a round bottom flask under reflux for $1 \mathrm{~h}$. It was cooled and the excess of $\mathrm{HCl}$ was removed under vacuum. The residue was dissolved in distilled water and made up to $50 \mathrm{~mL}$ with distilled water $(500 \mu \mathrm{g} / \mathrm{mL})$ to get a stock solution of hydrolysed drug (HREB). Working standard solutions of concentration of $25 \mu \mathrm{g} / \mathrm{mL}$ (for both the methods) were prepared from stock solution of HREB.

\section{Preparation of reagents}

All the chemicals and reagents used were of analytical grade and the freshly prepared solutions were used in the investigations. $1.569 \times 10^{-1} \mathrm{M}$ ethyl acetoacetate (EAA) solution was prepared by dissolving $2 \mathrm{~mL}$ EAA in $100 \mathrm{~mL}$ ethanol for Method $\mathrm{M}_{1} .18 \mathrm{M}$ sulphuric acid was used for this method.

$5.774 \times 10^{-2} \mathrm{M} p$-sulphanilic acid (SAc) solution was prepared by dissolving $1 \mathrm{~g}$ of $\mathrm{SAc}$ in $100 \mathrm{~mL}$ of $0.2 \mathrm{M} \mathrm{HCl}$ for method $\mathrm{M}_{2}$. In this method $5.796 \times 10^{-2} \mathrm{M} \mathrm{NaNO}_{2}$ and $1 \mathrm{M}$ $\mathrm{NaOH}$ solutions were prepared in triple distilled water. 


\section{Procedure for bulk samples}

\section{Method $M_{1}$}

Aliquots of hydrolyzed REB $\left(0.5-3.0 \mathrm{~mL}, 25 \mu \mathrm{g} \cdot \mathrm{mL}^{-1}\right)$ and $1 \mathrm{~mL}$ of $2 \%$ EAA solution were delivered into a series of $25 \mathrm{~mL}$ calibrated tubes. Then $2.5 \mathrm{~mL}$ of conc. $\mathrm{H}_{2} \mathrm{SO}_{4}$ was added slowly along the walls of each of tube and kept under running water for cooling. After 15 minutes, the total volume was brought up to the mark with ethanol. The absorbance was read against a reagent blank at $400 \mathrm{~nm}$ between 10-40 minutes.

\section{Method $M_{2}$}

To a series of $10 \mathrm{~mL}$ graduated test tubes, $0.8 \mathrm{~mL}$ of $\mathrm{SAc}$ and $1 \mathrm{~mL}$ of $\mathrm{NaNO}_{2}$ solutions were added and allowed to stand for 2 minutes. Aliquots of hydrolysed drug $\left(0.5-0.3 \mathrm{~mL}, 25 \mu \mathrm{g} \cdot \mathrm{mL}^{-1}\right)$ were delivered into the test tubes. Then $5 \mathrm{~mL}$ of $\mathrm{NaOH}$ solution was added and the volume in each tube was made up to $10 \mathrm{~mL}$ with distilled water. The absorbances of the solutions were measured after 5 minutes at $430 \mathrm{~nm}$ against a reagent blank.

\section{Procedure for pharmaceutical formulations}

An accurately weighed portion of tablet content equivalent to about $100 \mathrm{mg}$ of REB was transferred into a $100 \mathrm{~mL}$ volumetric flask. About $80 \mathrm{~mL}$ of warm methanol was added to it and shaken well for about 20 minutes. The contents were diluted with methanol up to the mark and mixed thoroughly. The solution was filtered and the filtrate was evaporated to dryness. The residue was used for the preparation of standard solution as shown under standard solution preparation of HREB. These solutions were analyzed as under procedures described for bulk solutions.

\section{Procedure for the assay of REB in formulations-reference method}

An accurately weighed portion of the powdered tablets equivalent to $20 \mathrm{mg}$ of drug was dissolved in $20 \mathrm{~mL}$ of methanol, shaken well and filtered. $10 \mathrm{~mL}$ of the filtrate was diluted to $50 \mathrm{~mL}$ with methanol to get $200 \mu \mathrm{g} / \mathrm{mL}$ solution of drug in formulations.

In order to get $100 \mu \mathrm{g} / \mathrm{mL}$ solution, $5 \mathrm{~mL}$ of the above solution was diluted to $10 \mathrm{~mL}$ with methanol. The absorbance of the solution was determined at $\lambda_{\max }, 274 \mathrm{~nm}$ (Figure 2). The quantity of the drug was computed from the Beer's law plot (Figure 3) of the bulk drug in methanol.

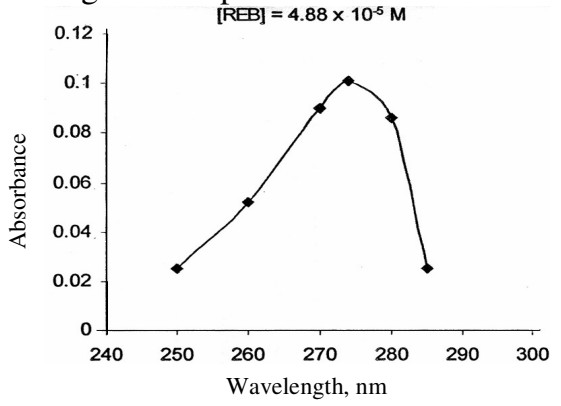

Figure 2. Absorption spectrum of REB in methanol (UV reference method)

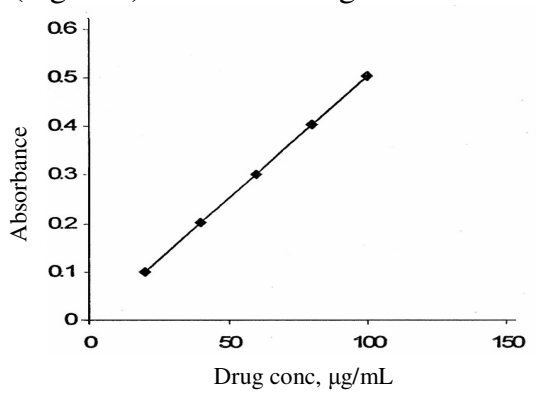

Figure 3. Beer's law plot of REB in methanol (UV reference method)

\section{Results and Discussion}

Spectral characteristics

In order to ascertain the optimum wavelength of maximum absorption $\left(\lambda_{\max }\right)$ of the coloured species formed in the above methods, specified amounts of REB were taken and colours were developed separately by following the above procedures. The amounts of REB present in total volume of coloured solutions were $2 \mu \mathrm{g} / \mathrm{mL}$ for method $\mathrm{M}_{1}$ and $7.5 \mu \mathrm{g} / \mathrm{mL}$ for method $\mathrm{M}_{2}$. 
The absorption spectra were scanned on a spectrophotometer in the wavelength region of 350 and $850 \mathrm{~nm}$ against a similar reagent blank or distilled water. The reagent blank absorption spectrum of each method was also recorded against distilled water. The results were graphically represented in Figure 4 (for Method $\mathrm{M}_{1}$ ) and Figure 5 (for Method $\mathrm{M}_{2}$ ). The absorption curves of the coloured species in each method show characteristic absorption maximum.

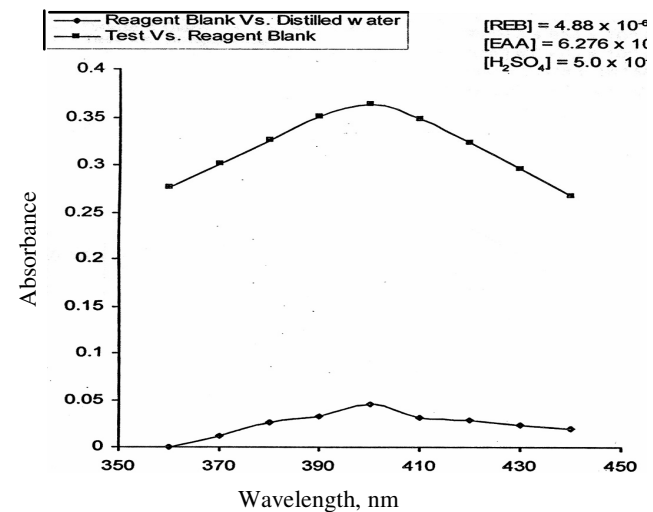

Figure 4. Absorbance spectrum of REB EAA-conc. $\mathrm{H}_{2} \mathrm{SO}_{4}\left(\mathrm{M}_{1}\right)$

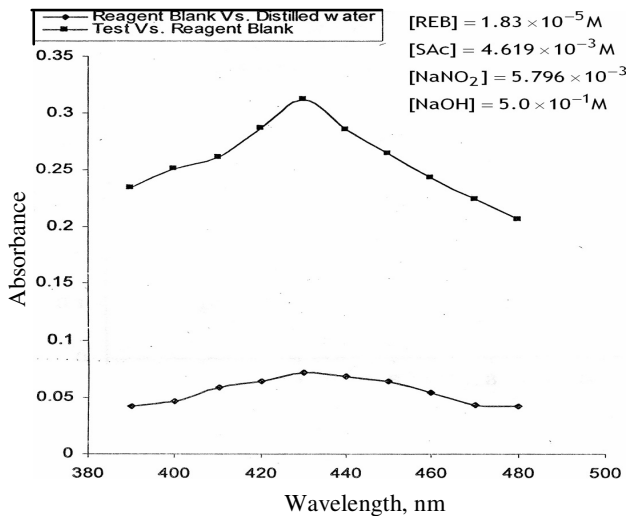

Figure 5. Absorbance spectrum of REB $\mathrm{SAc}-\mathrm{HNO}_{2}\left(\mathrm{M}_{2}\right)$

\section{Optimum conditions fixation in procedures}

The optimum conditions for the colour development of methods $\left(\mathrm{M}_{1}\right.$ and $\left.\mathrm{M}_{2}\right)$ were established by varying the parameters one at a time keeping the others fixed and observing the effect produced on the absorbance of the coloured species. The optimum range of absorption maximum for $\mathrm{M}_{1}$ is $395-405 \mathrm{~nm}$ and that for $\mathrm{M}_{2}$ is $425-435 \mathrm{~nm}$.

\section{Optical characteristics}

In order to test whether the coloured species formed in above methods adhere to Beer's law, the absorbances at appropriate wavelengths of a set of solutions containing varying amounts of REB and specified amounts of reagents were recorded against the corresponding reagent blanks. The Beer's law plots were recorded graphically (Figure 6 for $M_{1}$ and Figure 7 for $\mathbf{M}_{2}$ ). Beer's law limits, molar absorptivity, sandell's sensitivity and optimum photometric range (Figure 8 for $\mathrm{M}_{1}$ and Figure 9 for $\mathrm{M}_{2}$ ) for REB in each method were calculated. Least square regression analysis was carried out for getting the slope, intercept and the correlation coefficient values (Table 1)

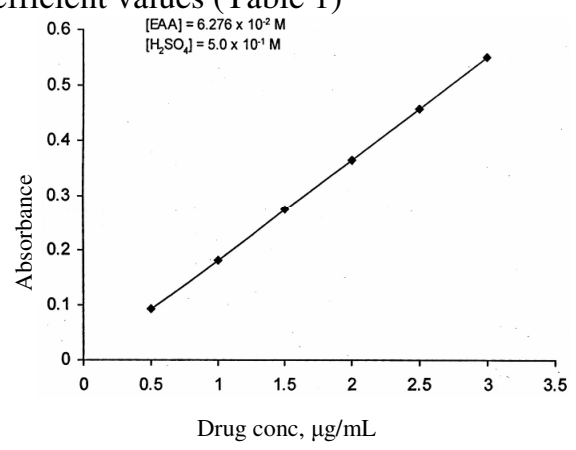

Figure 6. Beer's law plot of REB - EAAconc. $\mathrm{H}_{2} \mathrm{SO}_{4}\left(\mathrm{M}_{1}\right)$

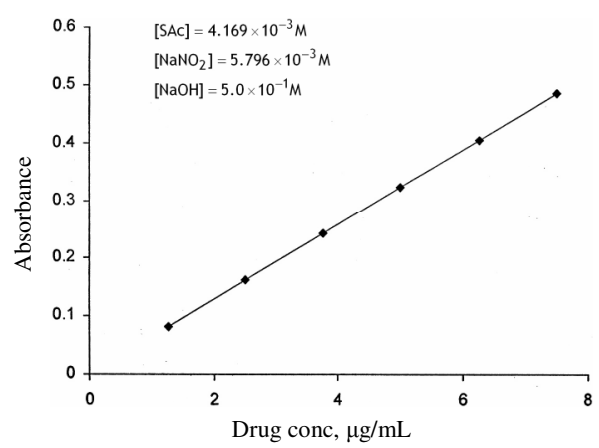

Figure 7. Beer's law plot of REB - SAc$\mathrm{HNO}_{2}\left(\mathrm{M}_{2}\right)$ 


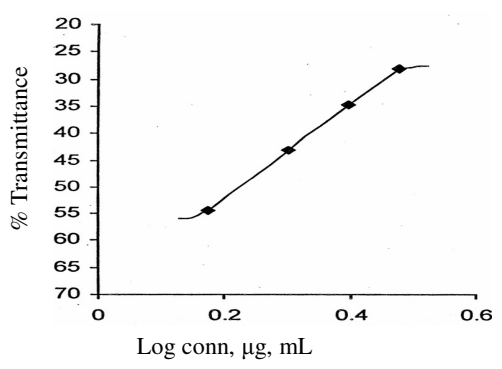

Figure 8. Ringbom plot of REBEAA-conc. $\mathrm{H}_{2} \mathrm{SO}_{4}\left(\mathrm{M}_{1}\right)$

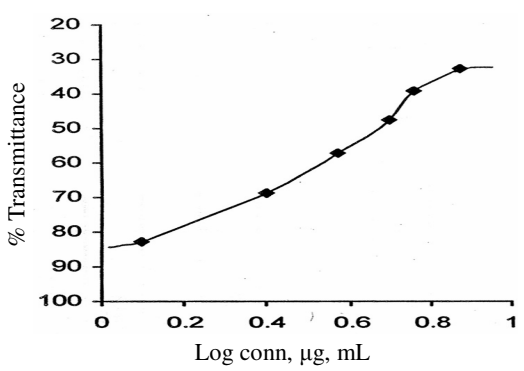

Figure 9. Ringbom plot of REB$\mathrm{SAc}-\mathrm{HNO}_{2}\left(\mathrm{M}_{2}\right)$

\section{Precision}

The precision of the proposed methods was ascertained from the absorbance values obtained by actual determination of six replicates of a fixed amount of REB in total solution. The percent relative standard deviation and percent range of error (at 0.05 and 0.01 confidence limits) were calculated for the proposed methods (Table 1).

\section{Accuracy}

To determine the accuracy of each proposed method, different amounts of bulk samples of REB within the Beer's law limits were taken and analysed by the proposed methods. The results (percent error) were recorded in Table 1.

Table 1. Optical and regression characteristics, precision and accuracy of the proposed methods for REB

\begin{tabular}{|c|c|c|}
\hline Parameters & $\begin{array}{c}\mathrm{M}_{1} \\
\left.\text { (EAA - Conc. } \mathrm{H}_{2} \mathrm{SO}_{4}\right)\end{array}$ & $\begin{array}{c}\mathrm{M}_{2} \\
\left(\mathrm{SAc}-\mathrm{HNO}_{2}\right)\end{array}$ \\
\hline$\lambda_{\max }, \mathrm{nm}$ & 400 & 430 \\
\hline Beer's law limits, $\mu \mathrm{g} / \mathrm{mL}$ & $0.5-3.0$ & $1.0-7.5$ \\
\hline Molar Absorptivity, $1 \mathrm{~mol}^{-1} \mathrm{~cm}^{-1}$ & $7.459 \times 10^{4}$ & $2.656 \times 10^{4}$ \\
\hline Detection limit, $\mu \mathrm{g} / \mathrm{mL}$ & $2.265 \times 10^{-2}$ & 1.002 \\
\hline Sandell's Sensitivity ( $\mu \mathrm{g}{ }^{\mathrm{cm}-} / 0.001$ Absorbance unit) & $3.113 \times 10^{-2}$ & $6.131 \times 10^{-2}$ \\
\hline Optimum Photometric range, $\mu \mathrm{g} / \mathrm{mL}$ & $1.5-3.0$ & $2.5-5.0$ \\
\hline Regression equation $(\mathrm{Y}=\mathrm{a}+\mathrm{bc})$ Slope $(\mathrm{b})$ & $1.828 \times 10^{-1}$ & $6.48 \times 10^{-2}$ \\
\hline Intercept (a) & $4.0 \times 10^{-4}$ & $8.0 \times 10^{-4}$ \\
\hline Standard error on estimation $\left(\mathrm{S}_{\mathrm{e}}\right)$ & $1.316 \times 10^{-3}$ & $2.065 \times 10^{-3}$ \\
\hline Standard deviation on slope $\left(\mathrm{S}_{\mathrm{b}}\right)$ & $8.326 \times 10^{-4}$ & $5.224 \times 10^{-3}$ \\
\hline Standard deviation on intercept $\left(\mathrm{S}_{\mathrm{a}}\right)$ & $1.381 \times 10^{-3}$ & $2.165 \times 10^{-2}$ \\
\hline Correlation coefficient (r) & 0.9999 & 0.9999 \\
\hline Relative Standard deviation, $\%^{*}$ & 1.11 & 1.227 \\
\hline$\%$ error in Bulk Samples ${ }^{* *}$ & -0.366 & -0.404 \\
\hline \multicolumn{3}{|l|}{$\%$ range of error (confidence limits) } \\
\hline 0.05 level & 1.165 & 1.288 \\
\hline 0.01 level & 1.827 & 2.02 \\
\hline
\end{tabular}

"Average of six determinations considered. ${ }^{* *}$ Average of three determinations.

Analysis of formulations

Commercial formulations (tablets) containing REB were successfully analysed by the proposed methods. The values obtained by the proposed and reference methods for formulations were compared statistically with $\mathrm{F}$ and $t$-tests and found not different significantly. 
The results were summarized in Table 2. Percent recoveries were determined by adding standard drug to pre-analysed formulations. The results of the recovery experiments by the proposed methods were also listed in Table 2.

\section{Interference studies}

The effect of wide range of excipients and other active ingredients usually present in the formulations for the assay of REB in both the methods under optimum conditions were investigated. The commonly used excipients present in formulations did not interfere even if they were present in excess amount than they usually exist.

Table 2. Assay of REB in pharmaceutical formulations

\begin{tabular}{|c|c|c|c|c|c|c|}
\hline \multirow{2}{*}{ Formulations* } & \multirow{2}{*}{$\begin{array}{l}\text { Labelled } \\
\text { amount, } \\
\text { mg }\end{array}$} & \multicolumn{2}{|c|}{$\begin{array}{l}\text { Amount found by proposed } \\
\text { methods** }\end{array}$} & \multirow{2}{*}{$\begin{array}{l}\text { Reference } \\
\text { Method }\end{array}$} & \multicolumn{2}{|c|}{$\begin{array}{l}\% \text { Recovery by proposed } \\
\text { methods*** }\end{array}$} \\
\hline & & $\begin{array}{c}\mathrm{M}_{1}\left(\mathrm{EAA}_{-}\right. \\
\left.\text {Conc. } \mathrm{H}_{2} \mathrm{SO}_{4}\right)\end{array}$ & $\begin{array}{c}\mathrm{M}_{2}\left(\mathrm{SAc}^{-}\right. \\
\left.\mathrm{HNO}_{2}\right)\end{array}$ & & $\begin{array}{c}\mathrm{M}_{1}(\mathrm{EAA}- \\
\left.\text { Conc. } \mathrm{H}_{2} \mathrm{SO}_{4}\right) \\
\end{array}$ & $\begin{array}{l}\mathrm{M}_{2}(\mathrm{Sac}- \\
\left.\mathrm{HNO}_{2}\right) \\
\end{array}$ \\
\hline \multirow{4}{*}{ Tablet I } & \multirow{5}{*}{4} & $3.975 \pm$ & $3.969 \pm$ & & & \\
\hline & & 0.021 & 0.020 & $3.975 \pm$ & $99.17 \pm$ & $99.15 \pm$ \\
\hline & & $\mathrm{F}=1.52$ & $\mathrm{~F}=1.38$ & 0.017 & 0.53 & 0.50 \\
\hline & & $\mathrm{t}=0.33$ & $\mathrm{t}=2.02$ & & & \\
\hline \multirow{4}{*}{ Tablet II } & & $3.939 \pm$ & $3.972 \pm$ & & & \\
\hline & \multirow{4}{*}{4} & 0.026 & 0.025 & $3.949 \pm$ & $98.49 \pm$ & $99.31 \pm$ \\
\hline & & $\mathrm{F}=1.91$ & $\mathrm{~F}=2.07$ & 0.036 & 0.65 & 0.63 \\
\hline & & $\mathrm{t}=1.60$ & $\mathrm{t}=0.68$ & & & \\
\hline \multirow{4}{*}{ Tablet III } & & $7.892 \pm$ & $7.953 \pm$ & & & \\
\hline & \multirow{3}{*}{8} & 0.034 & 0.041 & $7.912 \pm$ & $98.65 \pm$ & $99.41 \pm$ \\
\hline & & $\mathrm{F}=1.06$ & $\mathrm{~F}=1.54$ & 0.033 & 0.43 & 0.51 \\
\hline & & $\mathrm{t}=0.50$ & $\mathrm{t}=1.28$ & & & \\
\hline \multirow{4}{*}{ Tablet IV } & \multirow{4}{*}{8} & $7.906 \pm$ & $7.911 \pm$ & & & \\
\hline & & 0.010 & 0.020 & $7.789 \pm$ & $98.83 \pm$ & $98.90 \pm$ \\
\hline & & $\mathrm{F}=3.61$ & $\mathrm{~F}=1.11$ & 0.019 & 0.13 & 0.24 \\
\hline & & $\mathrm{t}=0.90$ & $\mathrm{t}=1.00$ & & & \\
\hline
\end{tabular}

${ }^{*}$ Tablets from different pharmaceutical companies or different batches of same company. ${ }^{* *}$ Average \pm standard deviation of six determinations, the $t$ - and $F$-test values refer to comparison of the proposed method with the reference method. Theoretical values at $95 \%$ confidence limit, $F=5.05, t=2.26 .{ }^{* * * *}$ Recovery of $10 \mathrm{mg}$ added to the preanalysed pharmaceutical formulations (average of three determinations)

\section{Chemistry of the coloured species}

Reboxetine possesses analytically useful functional groups such as phenoxy ethyl (acid hydrolysis yields phenolic hydroxyl, HREB) and morpholino (cyclic imino) moieties. The proposed methods were based on the reactivity of phenolic hydroxyl group. An attempt was made to indicate the nature of colour species in each proposed method for REB tentatively based on analogy and probability.

\section{Method $M_{1}$}

Condensation of phenolic compound (HREB) with ethyl acetoacetate in sulphuric acid medium, to give a coumarin derivative was the basis for this method. It was shown in Scheme 1.

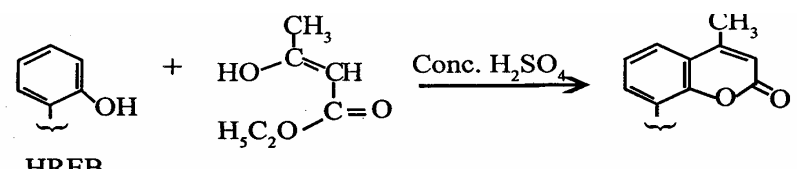

\section{Scheme 1}




\section{Method $\mathrm{M}_{2}$}

A study of the coloured product formation of HREB by the reaction with diazotized sulphanilic acid was carried out in the usual manner for diazotization and coupling under alkaline conditions with phenolic compound. The probable sequence of reactions based on analogy was given in Scheme 2.

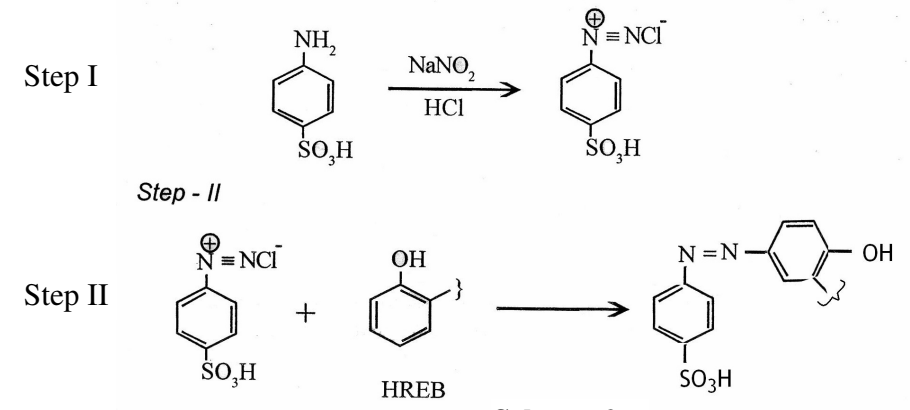

\section{Conclusion}

Scheme 2

The proposed methods exploit the phenoxy ethyl functional group in REB molecule. It can be seen from the results, that the proposed methods have good sensitivity and $\lambda_{\max }$. Statistical analysis of the results shows that the procedures adopted have good precision and accuracy. Results of the analysis of pharmaceutical formulations reveal that these methods are suitable for their analysis with virtually no interference of the usual additives. The proposed methods are simple, sensitive and reliable and can be used for the routine determination of REB in bulk samples and in pharmaceutical formulations depending upon the needs of the specific situation.

\section{References}

1. Ohman D, Norlander B, Peterson C and Bengtsson F, J Chromatogr A, 2002, 947(2), 247-254.

2. Ficarra R, Calabro M L, Tommasini S, Melardi S, Cutroneo P and Ficarra P, Chromatographia, 2001, 53(5-6), 261-265.

3. Frahnert C, Rao M L and Grasmaeder K, J Chromatogr B, 2003, 794(1), 35-47.

4. Barri T and Jonsson J A, Chromatographia, 2004, 59(3-4), 161-165.

5. Ohman D, Norlander B, Peterson C and Bengtsson F, Therapeutic Drug Monit., 2001, 23(1), 27-34.

6. Hartter S, Weigmann H and Hiemke C, J Chromatogr B, 2000, 740(1), 135-140.

7. Raggi M A, Mandrioli R, Casamenti G, Volterra V and Pinzauti S, J Chromatogr A, 2002, 949(1-2), 23-33.

8. Frigerio E, Pianezzola E and Strolin Bendetti M, J Chromatogr A, 1994, 660(1-2), 351-358.

9. Walters R R and Buist S C, J Chromatogr A, 1998, 828(1-2), 167-176.

10. Gutteck U and Rentsch K M, Clin Chem Lab Med., 2003, 41(12), 1571- 1579.

11. Raggi M A, Mandrioli R, Sabbionic C, Parenti C, Cannazza G and Fanali S, Electrophoresis, 2002, 23(12), 1870 - 1877.

12. Raggi M A, Bugamelli F, Sabbioni C, Ferranti A, Fanali S and Volterra V, J Pharm Biomed Anal., 2002, 27(1-2), 209 - 215.

13. Pelander A, Ojanpera I, Sistonen J, Rasanen I and Vuori E, J Anal Toxicol., 2003, 27(4), 226-232.

14. Nevin E, Anal lett., 2003, 36(6), 1183-1196. 


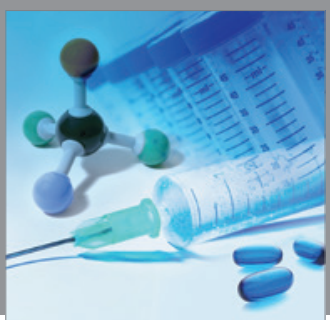

International Journal of

Medicinal Chemistry

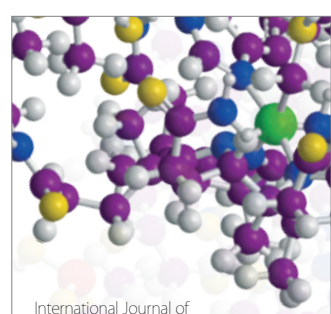

Carbohydrate Chemistry

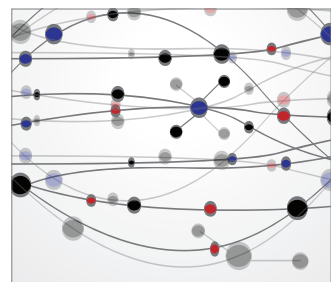

The Scientific World Journal
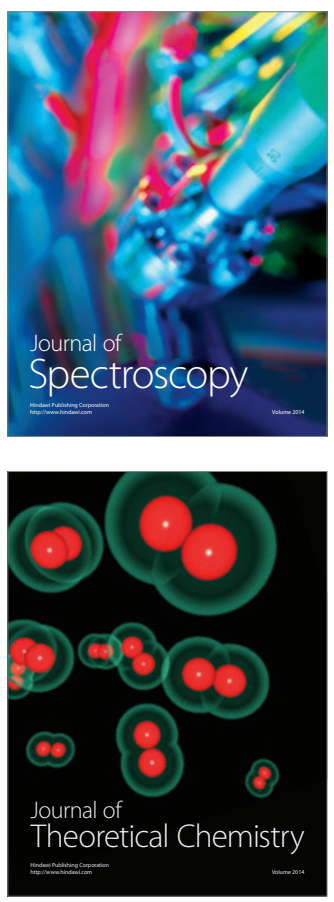
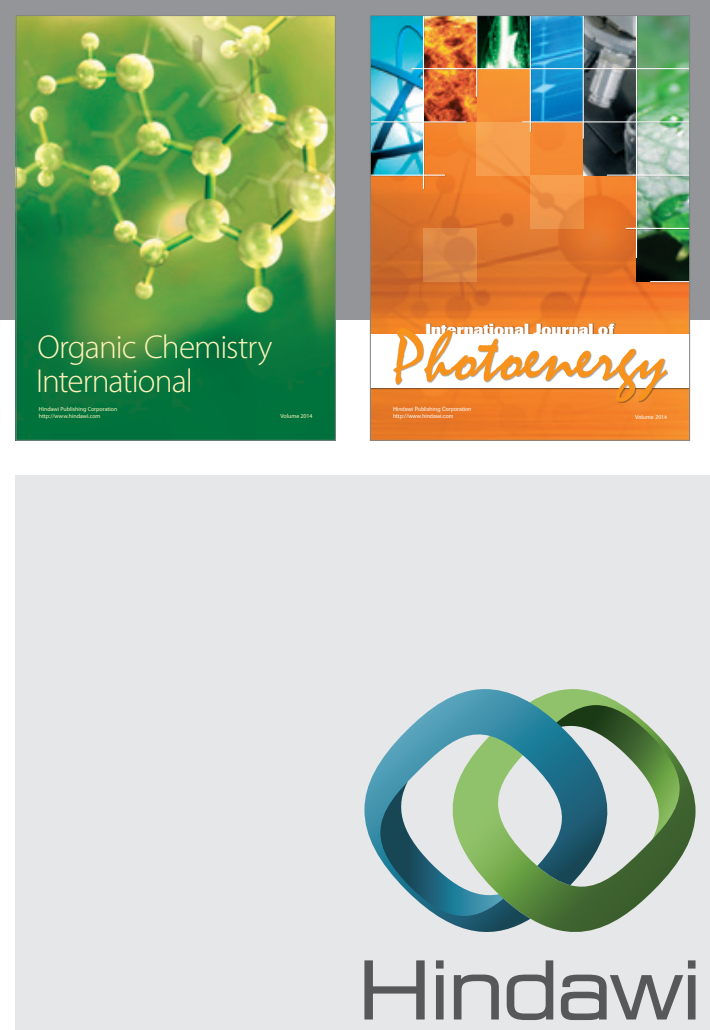

Submit your manuscripts at

http://www.hindawi.com
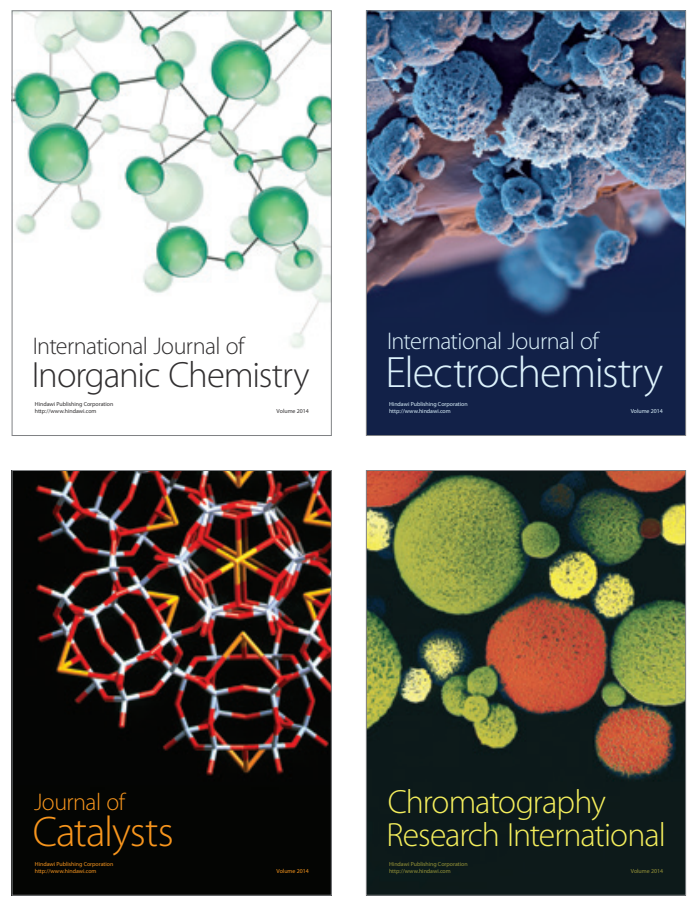
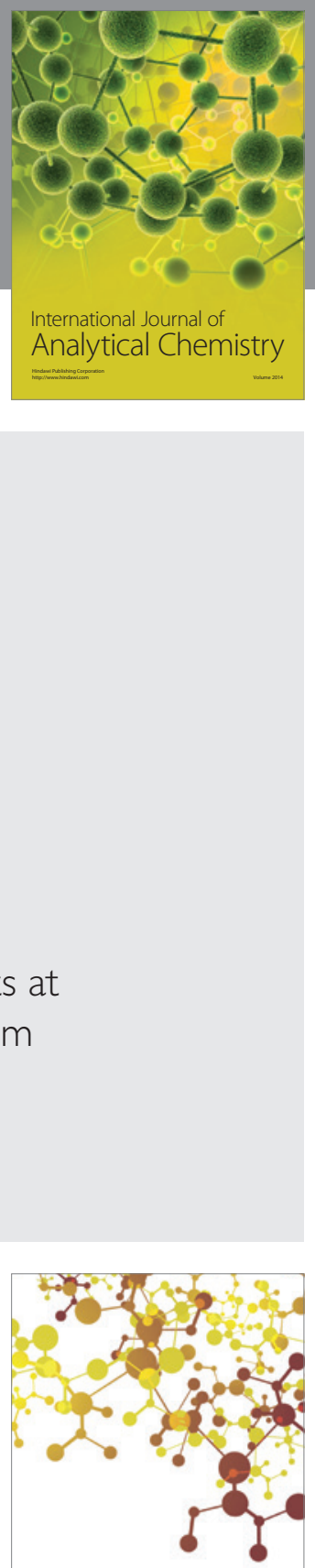

Journal of

Applied Chemistry
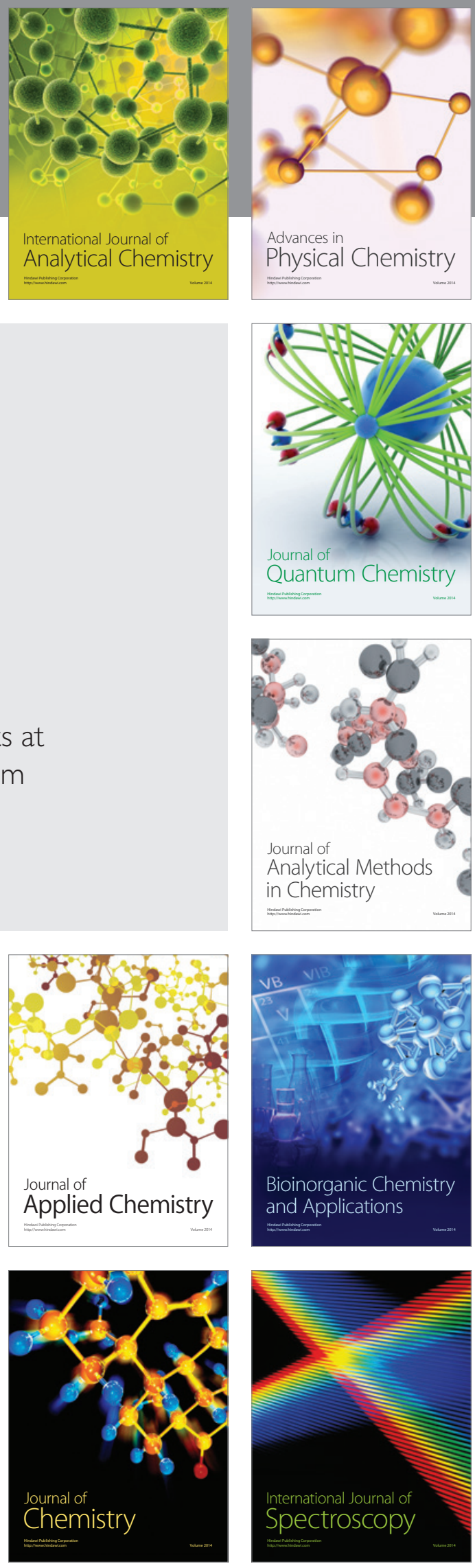